\title{
Modeling Pfiesteria piscicida population dynamics: a new approach for tracking size and mass in mixotrophic species
}

\author{
Xinsheng Zhang ${ }^{*}$, Jon T. Anderson, Raleigh R. Hood \\ Horn Point Laboratory, University of Maryland Center for Environmental Science, PO Box 775, Cambridge, \\ Maryland 21613, USA
}

\begin{abstract}
We have developed a generalized dynamic, numerical model to study Pfiesteria population dynamics based on available observations and literature. We have incorporated formulations into this model which allow us to track changes in cell size in relation to food availability and other environmental conditions, which can be used for modeling a variety of cell-size dependent physiological functions. With this model, we are able to follow the time dependency of both individual size and abundance of Pfiesteria zoospores in cultures. We also have developed a general, starvationbased trigger mechanism for cyst formation for mixotrophic species like Pfiesteria, which is based on the size of zoospores determined by previous food conditions and the decrease or increase in size determined by the current food conditions. The model results suggest that zoospore concentration can be regulated effectively by both bottom-up control by food availability and the top-down control by zooplankton grazing. Model sensitivity analysis shows that the results are fairly robust with respect to changes in the model parameter values. This paper represents a significant step forward in our efforts to model complicated life-cycle phenomena in dinoflagellates like Pfiesteria and, in so doing, also provides some important new approaches for tracking cell size and cyst formation.
\end{abstract}

KEY WORDS: Modeling $\cdot$ Pfiesteria size $\cdot$ Pfiesteria abundance $\cdot$ Encystment

\section{INTRODUCTION}

Pfiesteria piscicida is a mixotrophic, harmful algal bloom species that has a complex life cycle including flagellated, amoeboid and encysted stages as well as gametes and planozygotes (Burkholder et al. 1995, Burkholder \& Glasgow 1997). The flagellated stages of Pfiesteria consist of both toxic and nontoxic zoospores. The physical, chemical and biological conditions that give rise to toxic and nontoxic forms are not well understood (Burkholder et al. 1995, Burkholder \& Glasgow 1997). However, the presence and persistence of the toxic stages have been linked to the presence of fish (Burkholder et al. 1995, Burkholder \& Glasgow 1997) and have been implicated as a causative agent of many fish kills in the coastal waters of the southeastern US (Burkholder et al. 1995).
The complex behavior and life-cycle characteristics of Pfiesteria make this organism a fascinating and challenging modeling subject.

A variety of models of varying complexity have been developed to simulate the dynamics of harmful algal blooms (Franks 1997). Early models utilized simple predator-prey relationships, leaving out the effects of physical and chemical factors (Wyatt \& Horwood 1973). More recently, such simplified models have combined impacts of physical and chemical conditions on growth of harmful algae (Kishi \& Ikeda 1986, Donaghay \& Osborn 1997). However, because of its relatively recent discovery (Burkholder et al. 1992) and its complex life cycle (Burkholder \& Glasgow 1997), there are no existing models that have been developed specifically for studying the population dynamics of Pfiesteria. 
Although the specific feeding behavior of Pfiesteria is clearly influenced by the availability of different kinds of prey (i.e. fish: Burkholder \& Glasgow 1995), it is generally considered to be mixotrophic (Burkholder \& Glasgow 1997, Lewitus et al. 1999). That is, Pfiesteria is capable of both heterotrophic and autotrophic growth. Thus, a logical starting point for developing a model for simulating Pfiesteria population dynamics is provided by Stickney et al. (2000), who developed a set of generalized steady-state ecosystem models to study the impact of mixotrophy on nutrient dynamics in planktonic food webs. These models are composed of 5 components: inorganic nutrients, phytoplankton, mixotrophs, zooplankton and detritus. They also include representations of the 3 general types of mixotrophs described by Stoecker (1998): Type I, 'ideal mixotrophs' which are able to utilize phototrophy and phagotrophy equally well; Type II, primarily phototrophic phagocytic 'algae'; and Type III, predominately heterotrophic photosynthetic 'protozoa'. Pfiesteria spp. are believed to be among the latter group (Burkholder \& Glasgow 1997), which are often referred to as kleptoplastidic, i.e. having the ability to retain the chloroplasts of photosynthetic organisms it ingests and to utilize the carbon they fix.

However, the Stickney et al. (2000) Type III model was not designed for simulating the population dynamics of a complex organism like Pfiesteria, with its many different life cycle stages and ability to undergo transformations to and from benthic forms. In addition, the Stickney et al. (2000) models do not provide any means for tracking changes in cell size, which can be substantial in mixotrophic dinoflagellates like Pfiesteria under changing food (prey) concentrations. Moreover, some important aspects of dinoflagellate life cycles and population dynamics, such as the cyst formation and natural mortality rate, are believed to be closely related to the shrinkage in cell size during starvation conditions (Anderson 1997, J. M. Burkholder pers. comm.).

Here, we describe a generalized model based upon Stickney et al. (2000) that we have specifically designed for modeling 'Pfiesteria-like' dinoflagellates. This model has the added advantage that it can be used to model data sets in which changes in population size are reported in terms of abundance and/or total population mass (Burkholder \& Glasgow 1997, Stoecker et al. 2000). With this model, we are able to follow the time dependency of both individual size and abundance of zoospores, which provides a means to represent some of the unique aspects of Pfiesteria population dynamics, such as transformations from zoospores to cysts and zoospore mortality rate, which are believed to be closely related to cell size. Many physiological processes of plankton, such as growth, metabolism and reproduction are related to nutritional state and cell size (Caron et al. 1990, Anderson et al. 2003a). This paper therefore represents a significant step forward in our efforts to model complicated life-cycle phenomena in dinoflagellates like Pfiesteria, and also provides some important new approaches for tracking cell size and cyst formation in plankton populations.

Because information on the factors which control life-cycle transformations in Pfiesteria is incomplete (Burkholder \& Glasgow 1997), it would be unrealistic to build a complex model that attempts to include all the stages of Pfiesteria. Therefore, our general approach has been to keep this model as simple and general as possible. We have included only the physiological and life-stage characteristics that are necessary to reproduce fluctuations in a 'non-inducible' strain of Pfiesteria (i.e. NON-IND, undetectable toxicity in the presence or absence of fish: Burkholder et al. 2001). We have attempted to introduce general mechanisms that might be applicable to a variety of dinoflagellate strains as well as natural populations. The Pfiesteria strain we model here (Florida Department of Environmental Protection strain MDR23) does not appear to produce the wide range of life-cycle stages (e.g. benthic amoebae and palmalloid stages) that are observed in some of the toxic forms (Anderson et al. 2003a, J. M. Burkholder pers. comm.).

In addition to describing the model itself, we present 3 modeling 'experiments' designed to test and explore the behavior of this model. In the first, we simulate the interactions among inorganic nutrient, phytoplankton, detritus and Pfiesteria zoospores that were observed in a laboratory feeding experiment. Then, in 2 additional experiments, we add transformations from the Pfiesteria zoospore to cyst stage, and mortality due to zooplankton grazing, to explore the effects of these additional levels of complexity on the model behavior.

\section{MATERIALS AND METHODS}

Laboratory experiment. Results of a laboratory experiment were used to facilitate the development and validation of this model. A nontoxic Pfiesteria piscicida clone was used for the life history experiments. The clone was isolated from a Maryland strain cultured by the Florida Department of Environmental Protection (FDEP MDR23). Prior to the experiment, the Pfiesteria stocks were maintained on microalgal prey (Storeatula major) by pulse feeding every $2 \mathrm{~d}$. All stocks and experimental treatments were kept in $250 \mathrm{ml}$ plastic tissue culture flasks (VWR brand) containing Indian River, Delaware seawater diluted to $15 \mathrm{psu}, \mathrm{GF} / \mathrm{F}$ filtered, autoclaved and spiked with $\mathrm{f} / 2$-Si nutrients. The stocks were placed in Percival growth chambers at 
$20^{\circ} \mathrm{C}$ under moderate irradiance (83 $\mu \mathrm{mol}$ photons $\mathrm{m}^{-2} \mathrm{~s}^{-1}$ ) with a 12:12 h light:dark photoperiod.

The laboratory experiment was designed to enumerate algal prey concentrations and Pfiesteria flagellated stages (zoospores) over time, and elucidate the effects of changing prey concentrations on Pfiesteria zoospore populations. The light intensity used was $83 \mathrm{mmol}$ photons $\mathrm{m}^{-2} \mathrm{~s}^{-1}$ with a $12: 12 \mathrm{~h}$ light:dark photoperiod. At the beginning of the experiment, stock densities were determined by epifluorescence microscopy and each flask was inoculated with 500 zoospores $\mathrm{ml}^{-1}$. The addition of algal prey was designed as a 'semicontinuous/batch culture' hybrid. The initial algal prey density applied was 1000 cells $\mathrm{ml}^{-1}$ (a 2:1 prey:Pfiesteria ratio). For the first $24 \mathrm{~h}$, prey concentrations were readjusted to initial concentrations every $6 \mathrm{~h}$. For the remainder of the experiment, no additional prey was added to the flasks.

Flasks were sampled every $6 \mathrm{~h}$ for the first day, the second day and then every other day for $14 \mathrm{~d}$. For each sampling period, aliquots were preserved in glutaraldehyde (1.25\% final concentration) and refrigerated for at least $1 \mathrm{~h}$. For enumeration, the samples were stained with proflavin $\left(5.0 \mu \mathrm{g} \mathrm{ml}^{-1}\right.$ final concentration) and viewed using a blue light emission filter set and exciter (B-2E/C FITC ; EX 465-495, DM 505, BA 515-555). In addition to enumerating life stages, zoospore diameters were measured for a random sample of 30 individuals every $6 \mathrm{~h}$ on Days 1, 6 and 12 over the $14 \mathrm{~d}$ experiment.

The model. Carbon and nitrogen are the most commonly used model currencies and the choice of currency depends on the problem being studied (Carlotti et al. 2000). Here, we follow the approach of Fasham et al. (1990) and use nitrogen as the currency in our model. The major advantage of using nitrogen is that it often limits autotrophic growth in marine systems, whereas this is rarely the case with carbon. The model is composed of inorganic nutrient, phytoplankton, zooplankton, detritus, Pfiesteria zoospores and Pfiesteria cysts (Fig. 1). The mass in each of these compartments is expressed in $\mu \mathrm{M} N$. In addition to modeling the total biomass of Pfiesteria, we followed the time dependency of Pfiesteria zoospores' cell size (Msize) and abundance (Mnum). The cell size and abundance are expressed in pmol $\mathrm{N}$ and cells $\mathrm{ml}^{-1}$, respectively. Model initial conditions, parameter descriptions, symbols, values and units are listed in Tables $1 \& 2$. The conservation equations for each compartment are described below.

Zoospores: The rate of change of zoospore biomass $(\mathrm{M} / \mathrm{m})$ reflects the balance between herbivorous grazing and losses through expulsion, excretion, zooplankton grazing, cyst transformation, transformation shedding, and natural mortality.

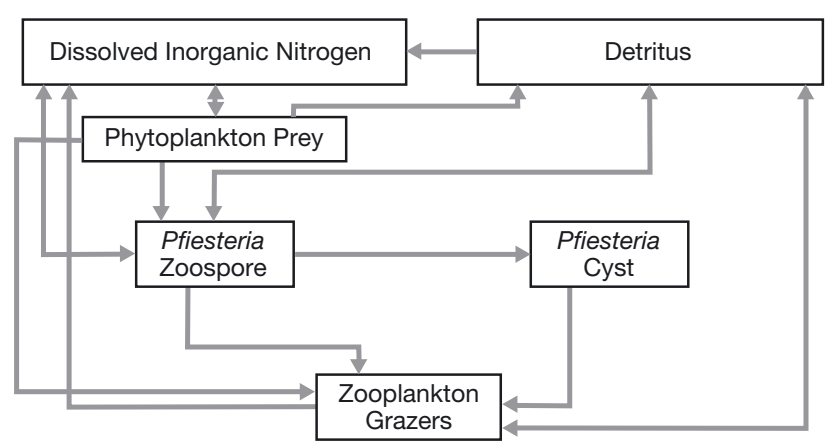

Fig. 1. Pfiesteria piscicida. The generalized 6 compartment model

\section{$\mathrm{dM} / \mathrm{d} t=$ GRAZINGm - EXPULSIONm - EXCRETIONm - GRAZINGmz - MtoC - TRANS_SHEDmc - MORTALITYm

In this model, we assume that zoospores only graze on phytoplankton. A Michaelis-Menten expression is used to define the grazing rate for zoospores on phytoplankton (GRAZINGm).

$$
\text { GRAZINGm }=(\mathrm{Gmm} \times \mathrm{P} \times \mathrm{M}) /(\mathrm{P}+\mathrm{MKs})
$$

Gmm is the maximum weight-specific grazing rate for zoospore and MKs is the half-saturation constant for zoospore grazing (Table 2).

The portion of food consumed by zoospores that cannot be assimilated is expelled. In this model, the zoospore expulsion rate from grazing on phytoplankton (EXPULSIONm) is assumed to be proportional to the grazing rate.

$$
\text { EXPULSIONm }=(1-\text { AEm) } \times \text { GRAZINGm }
$$

AEm is the assimilation efficiency of zoospore grazing on phytoplankton (Table 2).

\begin{tabular}{|c|c|c|c|}
\hline Description & Symbol & Value & Units \\
\hline Irradiance (light:dark) & I & $83 / 0$ & $\begin{array}{c}\mu \mathrm{mol} \text { photons } \\
\mathrm{m}^{-2} \mathrm{~s}^{-1}\end{array}$ \\
\hline Zoospore abundance & Mnum & 500 & cells $\mathrm{ml}^{-1}$ \\
\hline Cyst abundance & Cnum & 0 & cells $\mathrm{ml}^{-1}$ \\
\hline Zoospore size & Msize & 0.7 & pmol N \\
\hline Cyst size & Csize & 0.55 & pmol N \\
\hline Zoospore biomass & M & 0.35 & $\mu \mathrm{M} \mathrm{N}$ \\
\hline Cyst biomass & $\mathrm{C}$ & 0 & $\mu \mathrm{MN}$ \\
\hline Phytoplankton biomass & $\mathrm{P}$ & 1.4 & $\mu \mathrm{MN}$ \\
\hline Nutrient concentration & $\mathrm{N}$ & 883 & $\mu \mathrm{MN}$ \\
\hline Detritus concentration & $\mathrm{D}$ & 0 & $\mu \mathrm{MN}$ \\
\hline Zooplankton biomass ${ }^{\mathrm{a}}$ & Z & 0 & $\mu \mathrm{MN}$ \\
\hline Zooplankton biomass ${ }^{\mathrm{b}}$ & $\mathrm{Z}$ & 0 & $\mu \mathrm{MN}$ \\
\hline Zooplankton biomass ${ }^{\mathrm{C}}$ & $\bar{Z}$ & 1 & $\mu \mathrm{MN}$ \\
\hline
\end{tabular}

Table 1. Model initial conditions 
Table 2. Model parameters descriptions, symbols, and units

\begin{tabular}{|c|c|c|c|}
\hline Description & Symbol & Value & Units \\
\hline \multicolumn{4}{|l|}{ Parameters used in the first modeling experiment (standard) } \\
\hline Maximal zoospore size & Mmax & 1.4 & pmol N \\
\hline Critical zoospore size & Mcri & 0.5 & pmol N \\
\hline Zoospore specific mortality rate (normal/starvation) & $\mathrm{Sm}$ & $0.05 / 0.5$ & $\mathrm{~d}^{-1}$ \\
\hline Phytoplankton specific mortality rate & $\mathrm{Sp}$ & 0.12 & $d^{-1}$ \\
\hline Assimilation efficiency of zoospore & AEm & 0.70 & Dimensionless \\
\hline Active excretion efficiency of zoospore & AEXm & 0.30 & Dimensionless \\
\hline Zoospore basal specific excretion rate & $\mathrm{Bm}$ & 0.1 & $\mathrm{~d}^{-1}$ \\
\hline Maximum zoospore specific grazing rate & $\mathrm{Gmm}$ & 5.00 & $\mathrm{~d}^{-1}$ \\
\hline Maximum phytoplankton specific growth rate & $\mu_{\mathrm{mp}}$ & 1.42 & $\mathrm{~d}^{-1}$ \\
\hline Half-saturation constant for zoospore grazing & MKs & 3.00 & $\mu \mathrm{MN}$ \\
\hline Half-saturation constant for $\mathrm{N}$ uptake by $\mathrm{P}$ & PKs & 1.50 & $\mu \mathrm{MN}$ \\
\hline Light saturation parameter & $\mathrm{Ik}$ & 75 & $\mu \mathrm{mol}$ photons $\mathrm{m}^{-2} \mathrm{~s}^{-1}$ \\
\hline Partitioning parameter & $\mathrm{b}$ & 0.5 & Dimensionless \\
\hline Detritus specific remineralization rate & e & 0.05 & $d^{-1}$ \\
\hline \multicolumn{4}{|l|}{ Additional parameters used in the second modeling experiment } \\
\hline Upper size limit of zoospore transformation & $\mathrm{Mu}$ & 0.68 & pmol N \\
\hline Lower size limit of zoospore transformation & $\mathrm{Ml}$ & 0.58 & pmol N \\
\hline Zoospore abundance specific transformation rate from $\mathrm{M}$ to $\mathrm{C}$ & $\mathrm{Tmc}$ & 0.3 & $d^{-1}$ \\
\hline \multicolumn{4}{|l|}{ Additional parameters used in third modeling experiment } \\
\hline Zooplankton specific mortality rate & $\mathrm{Sz}$ & 0.05 & $\mathrm{~d}^{-1}$ \\
\hline Assimilation efficiency for $\mathrm{Z}$ on $\mathrm{P}$ & AEpz & 0.70 & Dimensionless \\
\hline Assimilation efficiency for $\mathrm{Z}$ on $\mathrm{M}$ & $\mathrm{AEmz}$ & 0.70 & Dimensionless \\
\hline Assimilation efficiency for $\mathrm{Z}$ on $\mathrm{C}$ & AEcz & 0.70 & Dimensionless \\
\hline Assimilation efficiency for Z on D & $\mathrm{AEdz}$ & 0.35 & Dimensionless \\
\hline Growth efficiency for $\mathrm{Z}$ on $\mathrm{P}$ & GEpz & 0.30 & Dimensionless \\
\hline Growth efficiency for $\mathrm{Z}$ on $\mathrm{M}$ & GEmz & 0.30 & Dimensionless \\
\hline Growth efficiency for $\mathrm{Z}$ on $\mathrm{C}$ & GEcz & 0.30 & Dimensionless \\
\hline Growth efficiency for $\mathrm{Z}$ on $\mathrm{D}$ & GEdz & 0.15 & Dimensionless \\
\hline Maximum zooplankton specific grazing rate & Gmz & 0.60 & $\mathrm{~d}^{-1}$ \\
\hline Half-saturation constant for zooplankton grazing & ZKs & 1.50 & $\mu \mathrm{MN}$ \\
\hline Zooplankton feeding preference on P & $\varnothing p$ & 1 & Dimensionless \\
\hline Zooplankton feeding preference on $\mathrm{M}$ & $\varnothing \mathrm{m}$ & 1 & Dimensionless \\
\hline Zooplankton feeding preference on $\mathrm{C}$ & $\varnothing_{\mathrm{c}}$ & 1 & Dimensionless \\
\hline Zooplankton feeding preference on D & $\varnothing \mathrm{d}$ & 1 & Dimensionless \\
\hline
\end{tabular}

To model the time dependency of total biomass, individual body size and abundance of Pfiesteria zoospores, we modify the approach of Steele (1974) and separate the zoospore excretion rate (EXCRETIONm) into the active excretion rate and basal excretion rate. In this model, we assume that the active excretion rate is proportional to the grazing rate and the basal excretion rate is independent of the grazing rate and is proportional to the biomass. Therefore, the basal excretion continues both in the presence and absence of food. During low and/or depleted food conditions, the zoospore size will decrease if the amount of assimilated food cannot satisfy the excretion losses.

$$
\begin{aligned}
\text { EXCRETIONm }= & {\left[\operatorname{AEXm}-\operatorname{AEXm}\left(1-\mathrm{e}^{-\mathrm{I} / \mathrm{lk}}\right)\right] \times } \\
& \operatorname{GRAZINGm}+\operatorname{BEXm} \times \mathrm{M}
\end{aligned}
$$

The active and basal excretion rates are expressed by the first and second term in Eq. (4), respectively. AEXm is the active excretion efficiency of zoospore grazing on phytoplankton, I is the irradiance, Ik is the saturation constant for light absorption and BEXm is the weight-specific basal excretion rate of zoospores (see Table 2).

Pfiesteria are believed to be the predominately heterotrophic photosynthetic 'protozoa' (Burkholder \& Glasgow 1997, Lewitus et al. 1999). Zoospores digest part of the algal cells and retain the chloroplasts of those cells (Lewitus et al. 1999). Therefore, Pfiesteria zoospores not only consume phytoplankton as zooplankton do, but they are believed to also use the photosynthesis to convert the nitrogen that would normally be excreted into organic matter when light conditions permit photosynthesis to occur. We follow the approach of Stickney et al. (2000) and represent the photosynthetic activity of kleptochloroplasts of Pfiesteria zoospores by a functional response between the active excretion of Pfiesteria zoospores and irradiance in the model. The active excretion rate decreases 
as the irradiance increases and approaches 0 when the irradiance is sufficiently high. These kleptochloroplasts have been observed to maintain their photosynthetic activity for days to weeks (Lewitus et al. 1999, Stoecker 1999). However, the decaying processes of the photosynthetic activity of kleptochloroplasts are not well understood. Anderson et al. (2003b) assumed that the photosynthetic potential of kleptochloroplasts decreases linearly with age, eventually ceasing at a set retention time. For the sake of simplicity, we do not include the retention effect of kleptochloroplasts in this model, i.e. the photosynthetic activity of kleptochloroplasts is only dependent on the zoospore grazing on phytoplankton at the current time.

In this model, we further assume that zooplankton graze on zoospores. GRAZINGmz is the zooplankton grazing rate in terms of zoospore biomass. The specific formulation is defined in the zooplankton component below. MtoC is the transformation rate from zoospores to cysts in terms of biomass, which happens when physiological and environmental conditions trigger the transformation.

$$
\text { MtoC }=\text { Tmc } \times \text { Mnum } \times \text { Csize }
$$

Tmc is the abundance specific transformation rate from zoospores to cysts (Table 2). Mnum is the zoospore abundance. Csize is the size of cysts. Transformations from zoospores to cysts, at most times, are associated with environmental stress (Burkholder \& Glasgow 1997, Anderson et al. 2003a, J. M. Burkholder pers. comm.). The resulting thick cyst wall is highly resistant to various perturbations (Burkholder \& Glasgow 1997). Cysts can transform back to zoospores when environmental conditions are favorable for zoospore growth (Burkholder \& Glasgow 1997). Some species of protozoa use encystment as a strategy for surviving starvation conditions (Corliss \& Esser 1974), and it has been suggested that this strategy is also employed by Pfiesteria (Burkholder \& Glasgow 1997, Anderson et al. 2003a, J. M. Burkholder pers. comm.). We therefore assume that the transformation from zoospores to cysts in Pfiesteria is a survival mechanism related to starvation, although the precise physiological and environmental conditions that trigger the transformations from zoospores to cysts are not clear at present. We further assume that the transformation from zoospores to cysts occurs only when food conditions are poor for an extended period (Fenchel 1982, Caron et al. 1990, Anderson 1997, Anderson et al. 2003a).

To integrate the current and previous food conditions into a trigger mechanism, we use the decrease or increase in the size of zoospores and the size of zoospores as the indexes of effects of the prolonged starvation conditions on physiological state of zoospores. The decrease or increase in the size of zoospores reflects the influence of the current food conditions. The size of zoospores reflects the accumulated influence of the previous food conditions. Specifically, when the size of the zoospores (Msize) falls within a predefined size window (due to previous starvation) (Table 2) and the amount of nitrogen assimilated is less than the metabolic losses (due to current starvation), transformation of Pfiesteria zoospores to Pfiesteria cysts is triggered. To represent that the size of 'starved' zoospores has shrunken to below the size range of actively growing zoospores, we assume that the upper limit of the encystment window is equal to $0.68 \mathrm{pmol}$ $\mathrm{N}$, which is slightly smaller than the size of newly divided zoospores (i.e. half the maximal zoospore size, 0.7 pmol N; Table 2). With this assumption, the transformation from zoospores to cysts does not occur during the period of regular growth and division because the size of zoospore is always larger than the upper limit of the encystment window when food is available. According to this mechanism, encystment is closely associated with the amount of reserved nitrogen in the dinoflagellate cells, which is consistent with observations by Anderson (1997). It is quite possible that the amount of the reserved nitrogen is positively related to the size of zoospores. For the sake of simplicity, we assume that the size of cysts is constant. Therefore, to transform from zoospores to cysts, the size of zoospores has to be larger or equal to the size of cysts. It is likely that some reserved nitrogen is needed to facilitate the transformation from zoospores to cysts. Therefore, we assume that the lower limit of the encystment window is slightly larger than the size of cysts (Table 2).

For each zoospore to cyst transformation, only the portion of the zoospore mass which is equal to the cyst mass is transformed to the cyst and the extra mass has to be shed during transformation from zoospores to cysts.

TRANS_SHEDmc is the extra mass shed during transformation from zoospores to cysts.

TRANS_SHEDmc $=$ Tmc $\times$ Mnum $\times($ Msize - Csize $)(6)$

MORTALITYm is the zoospore mortality rate in term of biomass.

$$
\text { MORTALITYm }=\mathrm{Sm} \times \mathrm{M}
$$

In this model, we assume that natural mortality rate of zoospores is proportional to zoospore biomass. $\mathrm{Sm}$ is the specific mortality rate of the zoospores (Table 2). For the sake of simplicity, mortality rate is usually considered to be constant (Carlotti et al. 2000). However, this approximation neglects that natural mortality rates may be different during critical periods such as starvation (Carlotti et al. 2000). In some models, mortality caused by starvation has been related to food concentration (Andersen \& Nival 1986) and to the specific growth rates of organisms (Carlotii \& Sciandra 1989). 
In this model, we assume that the value of the specific mortality rate $(\mathrm{Sm})$ is dependent on the size of zoospores and the food availability. With this assumption, the model is potentially able to reproduce the scenario where the abundance of zoospores quickly decreases under the prolonged starvation conditions.

The rate of change of zoospore abundance (Mnum) reflects the balance between zoospore division and losses through cyst transformation, natural mortality and zooplankton grazing.

$$
\begin{aligned}
\mathrm{dMnum} / \mathrm{d} t= & \text { DIVISIONm }- \text { MtoC_Num }- \\
& \text { MORTALITYm_Num }- \\
& \text { GRAZINGmz_Num }
\end{aligned}
$$

DIVISIONm is the zoospore division rate. When the amount of nitrogen assimilated is larger than the metabolic nitrogen losses, the size of the Pfiesteria zoospores increases. When the size of Pfiesteria zoospores reaches a maximum size (Mmax, see Table 2), they undergo cell division. The consequence of the cell division is that the size of the zoospores decreases to half of the maximum size and the abundance of the zoospores doubles.

MtoC_Num is the transformation rate from zoospores to cysts in term of abundance.

$$
\text { MtoC_Num = Tmc } \times \text { Mnum }
$$

MORTALITYm_Num is the zoospore mortality rate in term of abundance.

$$
\text { MORTALITYm_Num }=\mathrm{Sm} \times \text { Mnum }
$$

The zooplankton grazing rate in term of zoospore abundance (GRAZINGmz_Num) can be calculated from the mass-based grazing rate by dividing by size:

$$
\text { GRAZINGmz_Num = GRAZINGmz/Msize }
$$

Further, the size of zoospores at any given time can be calculated from the results of Eqs. (1) \& (8) by using:

$$
\text { Msize = M/Mnum }
$$

Cysts: In this model, we assume that zooplankton graze on cysts and losses of cysts from natural mortality are negligible. The rate of change of cyst biomass $(\mathrm{C} / \mathrm{c})$ therefore reflects the balance between the gain through transformation from zoospores to cysts and the loss through zooplankton grazing.

$$
\mathrm{dC} / \mathrm{d} t=\mathrm{MtoC}-\mathrm{GRAZINGcz}
$$

GRAZINGcz is zooplankton grazing rate in term of cyst biomass. The specific formulation will be defined in the zooplankton component below. The rate of change of cyst abundance (Cnum) reflects the same balance, i.e. gain through transformation and loss through grazing.

$$
\mathrm{dCnum} / \mathrm{d} t=\mathrm{MtoC} \_ \text {Num }- \text { GRAZINGcz_Num }
$$

The zooplankton grazing rate in term of cyst abundance (GRAZINGcz_Num) can be calculated by dividing the mass-based rate by cyst size:

$$
\text { GRAZINGcz_Num = GRAZINGcz/Csize }
$$

Although cysts certainly germinate, we did not see any evidence of excystment (i.e. empty cyst walls) during the $14 \mathrm{~d}$ laboratory experiments described in the 'Laboratory experiment' section. Therefore, we assume that transformations from cysts to zoospores are negligible in this model.

Zooplankton: The rate of change of zooplankton biomass $(\mathrm{Z} / \mathrm{z})$ reflects the balance between the gain through omnivorous grazing and losses through defecations, excretions and natural mortality.

$$
\begin{aligned}
\mathrm{dZ} / \mathrm{d} t= & \text { GRAZINGz }- \text { DEFECATIONz }- \\
& \text { EXCRETIONz - MORTALITYz }
\end{aligned}
$$

As with the zoospores, a Michaelis-Menten expression is used to define the grazing of zooplankton. In this model, we assume that zooplankton graze on phytoplankton (GRAZINGpz), zoospores (GRAZINGmz), cysts (GRAZINGcz) and detritus (GRAZINGdz).

$$
\begin{aligned}
& \text { GRAZINGz }=\text { GRAZINGpz }+ \text { GRAZINGmz }+ \\
& \text { GRAZINGcz }+ \text { GRAZINGdz } \\
& \text { GRAZINGpz }=(\mathrm{Gmz} \times \mathrm{P} \times \varnothing \mathrm{p} \times \mathrm{z}) / \theta \mathrm{z} \\
& \text { GRAZINGmz }=(\mathrm{Gmz} \times \mathrm{M} \times \varnothing \mathrm{m} \times \mathrm{Z}) / \theta \mathrm{z} \\
& \text { GRAZINGcz }=(\mathrm{Gmz} \times \mathrm{C} \times \varnothing \mathrm{c} \times \mathrm{z}) / \theta \mathrm{z} \\
& \text { GRAZINGdz }=(\mathrm{Gmz} \times \mathrm{D} \times \varnothing \mathrm{d} \times \mathrm{Z}) / \theta \mathrm{z} \\
& \theta \mathrm{z}=\varnothing \mathrm{p} \times \mathrm{P}+\varnothing \mathrm{m} \times \mathrm{M}+\varnothing \mathrm{c} \times \mathrm{C}+\varnothing \mathrm{d} \times \mathrm{D}+\mathrm{ZKs}
\end{aligned}
$$

Gmz is the maximum specific rate for zooplankton grazing and ZKs is the half-saturation constant for zooplankton grazing. $\varnothing \mathrm{p}, \varnothing_{\mathrm{m}}, \varnothing_{\mathrm{c}}$ and $\varnothing \mathrm{d}$ are the zooplankton feeding preferences on phytoplankton, zoospores, cysts and detritus, respectively. Various approaches have been used to parameterize feeding preferences on multiple prey types in zooplankton models. McCreary et al. (1996) and Hood et al. (2001) implemented a constraint that the sum of the feeding preferences is equal to 1 . This constraint implies that different food sources are irreplaceable, i.e. organisms will not use an alternative food source to replace one which is not available. This is not, however, the case for most of omnivorous zooplankton (Gifford \& Dagg 1988, Atkinson 1995). To make the model more realistic, we do not implement this constraint. Rather, the zooplankton feeding preference on each food source scales from 0 to 1 , independently. Zooplankton selective feeding can be simulated by varying the value of zooplankton feeding preference on each food source. For the sake of simplicity, we assume that the omnivo- 
rous zooplankton consume phytoplankton, zoospores, cysts and detritus indiscriminately, i.e. all preference values are set equal to 1 . This assumption implies that the omnivorous zooplankton maximize their grazing rate on whatever food source is available.

The portion of food consumed by zooplankton that cannot be assimilated is defecated. Based on the origin of food sources, zooplankton defecation (DEFECATIONz) can be separated into defecation from phytoplankton (DEFECATIONpz), zoospores (DEFECATIONmz), cysts (DEFECATIONcz) and detritus (DEFECATIONdz).

$$
\begin{gathered}
\text { DEFECATIONz = DEFECATIONpz + } \\
\text { DEFECATIONmz + DEFECATIONcz + } \\
\text { DEFECATIONdz } \\
\text { DEFECATIONpz = }(1-\text { AEpz }) \times \text { GRAZINGpz } \\
\text { DEFECATIONmz }=(1-\text { AEmz }) \times \text { GRAZINGmz } \\
\text { DEFECATIONcz }=(1-\text { AECz }) \times \text { GRAZINGcz } \\
\text { DEFECATIONdz }=(1-\text { AEdz }) \times \text { GRAZINGdz }
\end{gathered}
$$

AEiz are the assimilation efficiencies for zooplankton feeding on phytoplankton $(i=p)$, zoospores $(i=m)$, cysts $(\mathrm{i}=\mathrm{c})$ and detritus $(\mathrm{i}=\mathrm{d})$.

The major focus of this model is on Pfiesteria zoospores and Pfiesteria cysts. To model the time dependency of total biomass, individual body size and abundance of Pfiesteria zoospores, we have to separate the Pfiesteria zoospore excretion into active and basal excretion. Most of the published data do not separate these 2 types of excretions (Carlotti et al. 2000). For the sake of simplicity, we do not differentiate the basal excretion and the active excretion for zooplankton. This is a common approach in modeling the time dependency of zooplankton biomass (Carlotti et al. 2000). Like zooplankton defecation, zooplankton excretion (EXCRETIONz) can be separated into excretion from phytoplankton (EXCRETIONpz), zoospores (EXCRETIONmz), cysts (EXCRETIONCz) and detritus (EXCRETIONdz).

$$
\begin{aligned}
& \text { EXCRETIONz }=\text { EXCRETIONpz }+ \text { EXCRETIONmz }+ \\
& \text { EXCRETIONcz }+ \text { EXCRETIONdz } \\
& \text { EXCRETIONpz }=(\text { AEpz }- \text { GEpz }) \times \text { GRAZINGpz } \\
& \text { EXCRETIONmz }=(\text { AEmz }- \text { GEmz }) \times \text { GRAZINGmz } \\
& \text { EXCRETIONcz }=(\text { AEcz }- \text { GECz }) \times \text { GRAZINGcz } \\
& \text { EXCRETIONdz }=(\text { AEdz }- \text { GEdz }) \times \text { GRAZINGdz }
\end{aligned}
$$

GEiz are the growth efficiencies for zooplankton feeding on phytoplankton $(i=p)$, zoospores $(i=m)$, cysts $(i=c)$, and detritus $(i=d)$.

In this model, we assume a simple linear natural mortality rate for zooplankton (MORTALITYz).

$$
\text { MORTALITYz }=\mathrm{Sz} \times \mathrm{Z}
$$

where $\mathrm{Sz}$ is the specific mortality rate of zooplankton.

Phytoplankton: The rate of change of phytoplankton biomass $(\mathrm{P} / \mathrm{p})$ reflects the balance between nutrient uptake and losses through grazing and mortality.

$$
\begin{aligned}
\mathrm{dP} / \mathrm{d} t= & \text { UPTAKEp }- \text { GRAZINGz }- \\
& \text { GRAZINGm }- \text { MORTALITYp }
\end{aligned}
$$

UPTAKEp is the light- and concentration-dependent uptake rate of nutrient by phytoplankton.

$$
\text { UPTAKEp }=\mu_{m p}\left(1-\mathrm{e}^{-\mathrm{I} / \mathrm{Ik}}\right)[\mathrm{N} /(\mathrm{N}+\mathrm{PKs})] \times \mathrm{P}
$$

$\mu_{\mathrm{mp}}$ is the maximum phytoplankton specific growth rate and PKs is the half-saturation constant for phytoplankton nutrient uptake.

In this model, we assume that natural mortality rate of phytoplankton (MORTALITYp) occurs linearly:

$$
\text { MORTALITYp }=\mathrm{Sp} \times \mathrm{P}
$$

where $\mathrm{Sp}$ is the specific mortality rate of phytoplankton.

Nutrient: The sources of nutrients come from excretion, remineralization of detritus by bacteria and the direct remineralization of dissolved organic nitrogen released from dying organisms and shedding biomass. The sink of nutrient is phytoplankton nutrient uptake. The rate of change of nutrient concentration $(\mathrm{N} / \mathrm{n})$ is expressed as:

$$
\begin{aligned}
\mathrm{dN} / \mathrm{d} t= & \text { EXCRETIONm + EXCRETIONz + } \\
& \text { REMINERALIZATION + }(1-\mathrm{b}) \times \\
& (\text { MORTALITYp + MORTALITYm + } \\
& \text { MORTALITYz + TRANS_SHEDmc })- \\
& \text { UPTAKEp }
\end{aligned}
$$

We assume that detritus exhibits a linear rate of remineralization:

$$
\text { REMINERALIZATION }=\mathrm{e} \times \mathrm{D}
$$

where e is detritus specific remineralization rate.

Bacteria are not explicitly represented in this model. Rather, their effect is incorporated into the system through the detrital remineralization rate, e. Following Stickney et al. (2000), we incorporate the effect of the direct remineralization of organic nitrogen released from dying phytoplankton, zoospores, zooplankton and shedding biomass during transformation from zoospores to cysts by the partitioning parameter (b) (Table 2), which determines the proportion of the dying mass that is directly remineralized versus the proportion that ends up in the detritus pool. For the sake of simplicity, we follow Stickney et al. (2000) and set $\mathrm{b}=0.5$.

Detritus: The sources of detritus come from zooplankton defecations, zoospore expulsion, dead bodies of organisms and zoospore transformation shedding. The sinks from the detritus pool are grazing and rem- 
ineralization. The rate of change of detritus concentration $(\mathrm{D} / \mathrm{d})$ is expressed as:

$$
\begin{aligned}
\mathrm{dD} / \mathrm{d} t= & \text { DEFECATIONz + EXPULSIONm }+\mathrm{b} \times \\
& \text { (MORTALITYp + MORTALITYm + } \\
& \text { MORTALITYz + TRANS_SHEDmc) }- \\
& \text { GRAZINGdz }- \text { REMINERALIZATION }
\end{aligned}
$$

Model parameters. The model initial conditions are mainly based on the conditions of our laboratory experiment. The maximal zoospore size was based on measured values by Li (1998) for a similar diameter mixtrotrophic dinoflagellate, Gymnodinium galatheanum (= Gyrodinium galatheanum) (Li 1998). The size of well-fed Gymnodinium galatheanum is $1.3 \mathrm{pmol} \mathrm{N}$ (Li 1998). Therefore, we set the maximal zoospore size (the size which zoospores undergo cell division) to be 1.4 pmol N (Table 2). The mean zoospore diameter at the beginning of our laboratory experiment was 8.6 $\mu \mathrm{m}$. The maximal mean zoospore diameter is $11.4 \mu \mathrm{m}$. If we represent the shape of zoospore as an ellipsoid, this change in diameter represents a doubling of cell volume. If we assume the volume to weight conversion is a constant, then a doubling in volume is equivalent to doubling in weight. Therefore, we set zoospore size to be equal to half of the maximal zoospore size at the beginning of the model simulation (Table 1).

To demonstrate the transformations from zoospores to cysts in the modeling experiment, we arbitrarily assume that the abundance specific transformation rate from zoospores to cysts to be equal to $0.3 \mathrm{~d}^{-1}$ (Table 2). We need more data to validate the value of the transformation rate. We define a critical zoospore size (Table 2) and assume that zoospore specific mortality rate increases from 0.05 to $0.5 \mathrm{~d}^{-1}$ (Table 2) when the size of the Pfiesteria zoospores becomes smaller than the critical size and the amount of nitrogen assimilated by zoospores is less than their metabolic losses. Although we need more data to validate values of the critical zoospore size and the mortality rate, the starvation mortality rate is derived by fitting an exponential model to the zoospore abundance from Day 8 to 14 on the laboratory experiment (Fig. 2).

We separated the zoospore excretion into active and basal. Because most studies do not separate these 2 types of excretions (Carlotti et al. 2000), it is very difficult to find the values of the active excretion efficiency and the specific basal excretion rate from published data. We assume that the value of the active excretion efficiency is equal to the difference between typical values of assimilation efficiency and growth efficiency (specifically, using the effi- ciencies from Fasham et al. 1990) and that the value of the basal excretion rate is based on the specific respiration rate of similar sized flagellates at starvation (Fenchel \& Finlay 1983, Caron et al. 1990).

The maximum growth rate for Pfiesteria zoospores is between 1 and $2 \mathrm{~d}^{-1}$ (Glasgow et al. 1998, Stoecker et al. 2000). We assume that the growth efficiency of zoospores is $30 \%$. Then, to obtain a growth rate of $1.5 \mathrm{~d}^{-1}$, zoospores must gain 5 times their body nitrogen content from grazing per day. Therefore, we set the maximum weight-specific grazing rate for zoospore to be equal to $5 \mathrm{~d}^{-1}$ (see Table 2).

The values of the maximum phytoplankton-specific growth rate and the phytoplankton-specific mortality rate were calculated from laboratory experiments (Anderson et al. 2003b). The other parameters listed in Table 2 are based on published values (Fasham et al. 1990, Stickney et al. 2000).

\section{RESULTS AND DISCUSSION}

\section{Laboratory experiment}

Phytoplankton were depleted by Day 2 (Fig. 2A). Measured zoospore abundance and zoospore diameters are shown in Fig. 2B. During the first $18 \mathrm{~h}$, zoo-
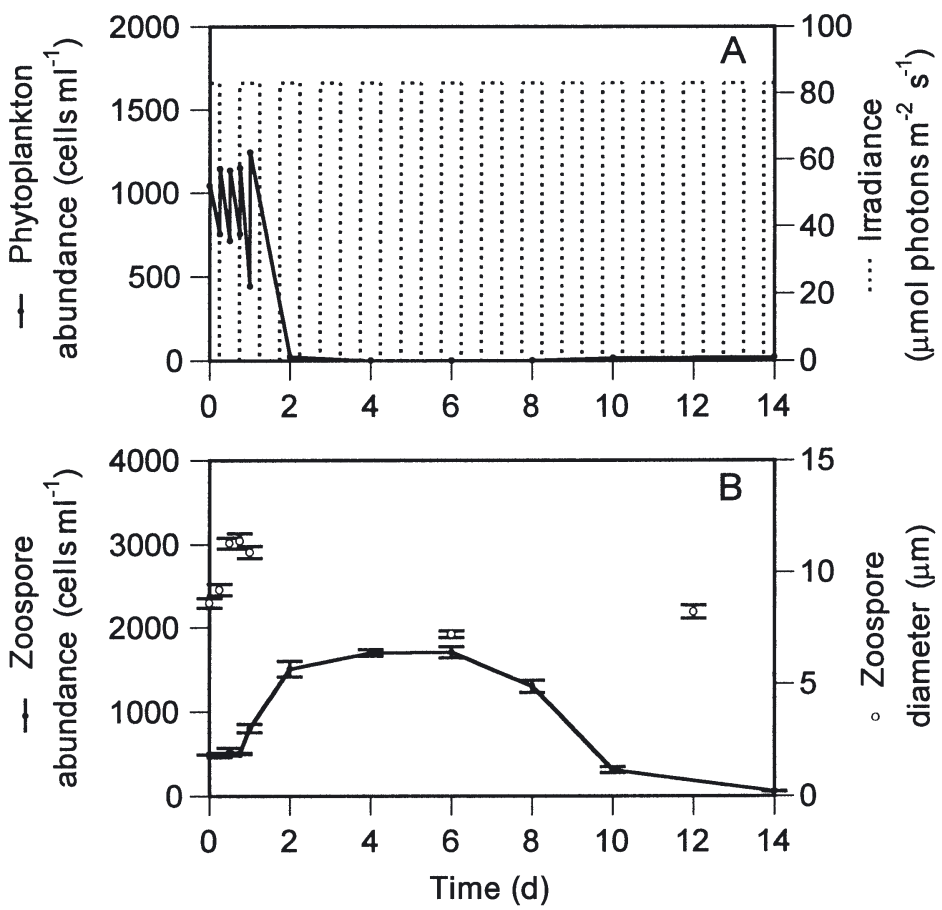

Fig. 2. Laboratory experiment with a $12: 12 \mathrm{~h}$ light:dark cycle in $\mathrm{f} / 2$ media.(A) Phytoplankton prey (Storeatula major) abundance versus time. (B) Pfiesteria zoospore abundance and size versus time. Means are shown with bars indicating SE 
spore abundance did not increase significantly $(p>$ 0.05, ANOVA, Tukey's honestly significant difference [HSD] post-comparison test), but the average cell diameters significantly increased from an initial mean of 8.6 to $11.4 \mu \mathrm{m}(\mathrm{p}<0.05$, ANOVA, Tukey's HSD postcomparison test) (Fig. 2B). Zoospore abundance significantly increased from $500 \mathrm{cells} \mathrm{ml}^{-1}$ at the beginning of the experiment to 1706 cells ml $^{-1}$ on Day 6 of the experiment $(\mathrm{p}<0.05$, ANOVA, Tukey's HSD postcomparison test) (Fig. 2B). Between Days 2 and 8, zoospore abundance remained above 1300 cells ml $^{-1}$ (Fig. 2B). After Day 8, zoospore abundance decreased significantly $(p<0.05$, ANOVA, Tukey's HSD postcomparison test).

After Day 1, cell abundance was measured on Days $2,4,6,8,10$ and 14 , but cell size was measured only on Days 6 and 12 of the $14 \mathrm{~d}$ experiment, which makes it difficult to do time series comparisons between abundance and diameter. On Day 6, the zoospore mean diameter was even smaller than in the initial condition ( $p<0.05$, ANOVA, Tukey's HSD post-comparison test) (Fig. 2B), which may be due to zoospores depleting internal nutrient stores or digesting food vacuoles during starvation conditions. However, the zoospore mean diameter on Day 12 was a little bit larger than on Day 6 ( $p<0.05$, ANOVA, Tukey's HSD postcomparison test) and the difference in the mean diameter between Day 12 and the initial condition was not statistically significant ( $p>0.05$, ANOVA, Tukey's HSD postcomparison test) (Fig. 2B).

\section{First modeling experiment}

In the first modeling experiment, we attempted to mimic the laboratory measurements. Therefore, we only included nutrients, phytoplankton, Pfiesteria zoospores and detritus in the model. We turned the transformation of Pfiesteria zoospores to Pfiesteria cysts off and also excluded zooplankton grazing. Like the laboratory experiment, the modeling experiment was run in nutrient-replete and low irradiance (83 $\mu \mathrm{mol}$ photons $\mathrm{m}^{-2} \mathrm{~s}^{-1}$ ) conditions with a $12: 12 \mathrm{~h}$ light:dark cycle.

We also readjusted phytoplankton concentration to initial concentration every $6 \mathrm{~h}$ for the first $24 \mathrm{~h}$ of the model simulation, as in the laboratory experiment. For the remainder of the model run, no additional phytoplankton was added. Fig. 3A shows that phytoplankton biomass fluctuates during the first $24 \mathrm{~h}$ of the model run due to the phytoplank- ton addition every $6 \mathrm{~h}$. But once the additions stop, phytoplankton biomass is exhausted by zoospore grazing after $4 \mathrm{~d}$ (Fig. 3A). Thus, as observed, the phytoplankton population is kept in check by the top-down control of the high zoospore grazing pressure in the model. However, the phytoplankton abundance in the experiment goes to 0 by Day 2, whereas the phytoplankton persist until Day 4 in the model. This suggests that the maximum grazing rate of Pfiesteria $\left(\mathrm{Gmm}=5 \mathrm{~d}^{-1}\right)$ in the model is a little too low and/or our phytoplankton growth rate $\left(\mu_{\mathrm{mp}}=1.42 \mathrm{~d}^{-1}\right)$ is a little too high. Given that these values were derived from different sources (see 'Model parameters') and that the model is moderately sensitive to both parameters (Table 3A), it is not surprising that this discrepancy exists. We consider that the time-dependent change of phytoplankton concentration in the model is generally consistent with the laboratory observations (correlation coefficient, $r=0.96, p<0.05$; because the units of phytoplankton abundance in the experiment and phytoplankton concentration in the model are different, we can use only the correlation coefficient to compare roughly the general patterns.) (Figs. 2A \& 3A).

The model successfully simulates the 3 phases of change in zoospore abundance that are observed (linear regression between the model and the experi-
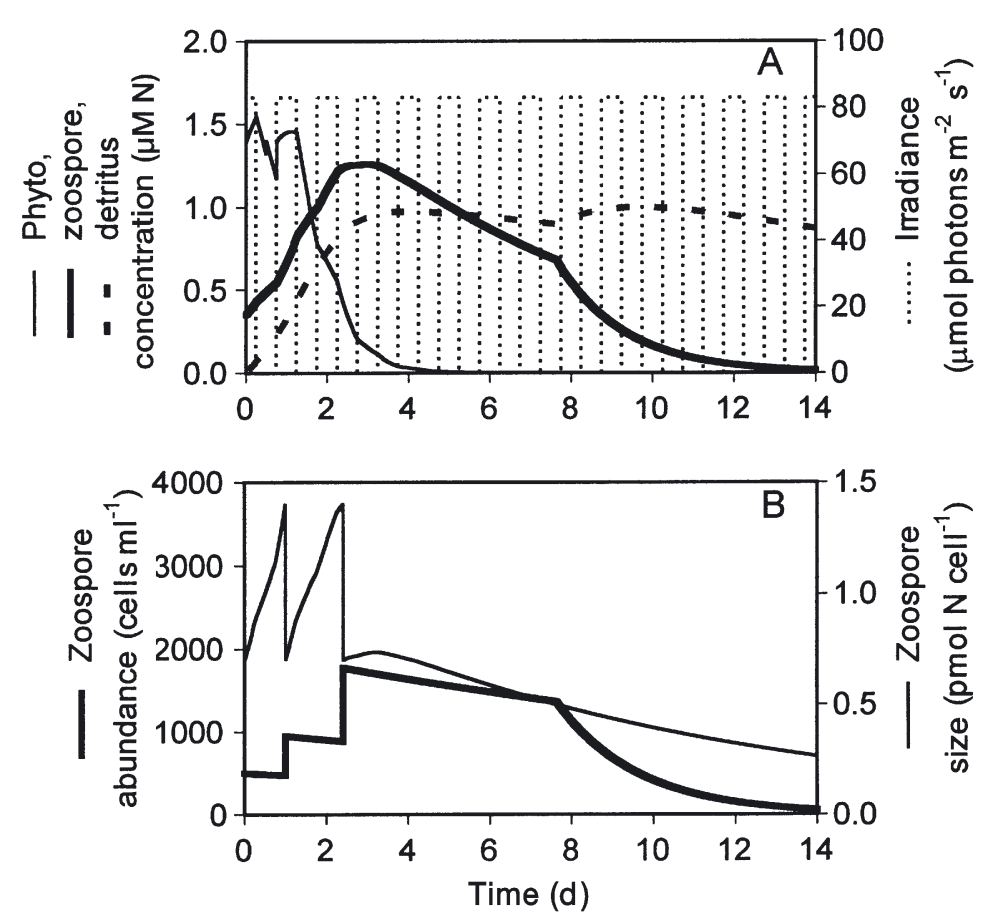

Fig. 3. First modeling experiment with $12: 12 \mathrm{~h}$ light:dark cycle in $\mathrm{f} / 2$ media. (A) Pfiesteria zoospore biomass, phytoplankton biomass and detritus concentration versus time. Nutrient concentration is off-scale and is not shown. (B) Pfiesteria zoospore abundance and size versus time 

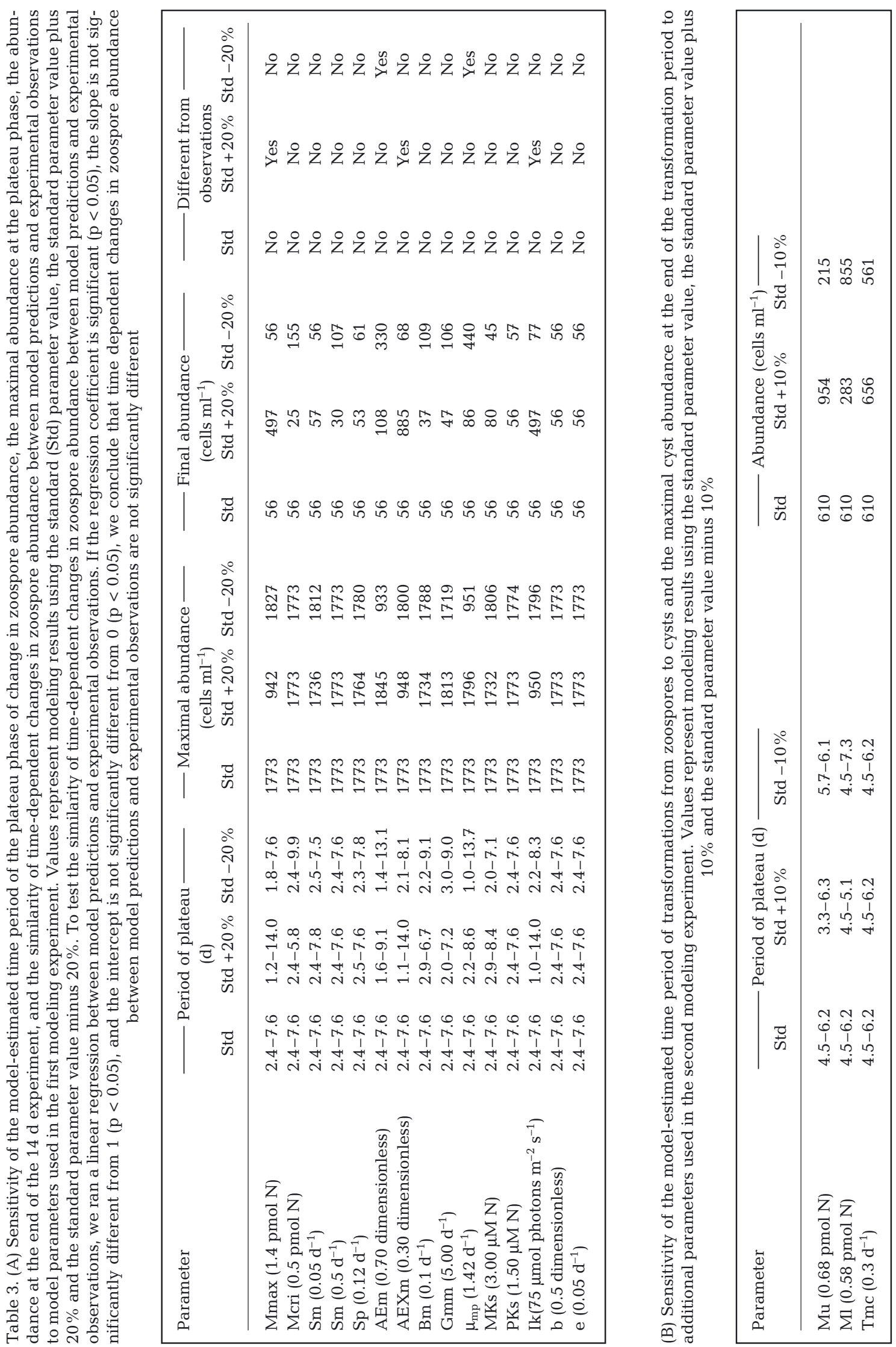


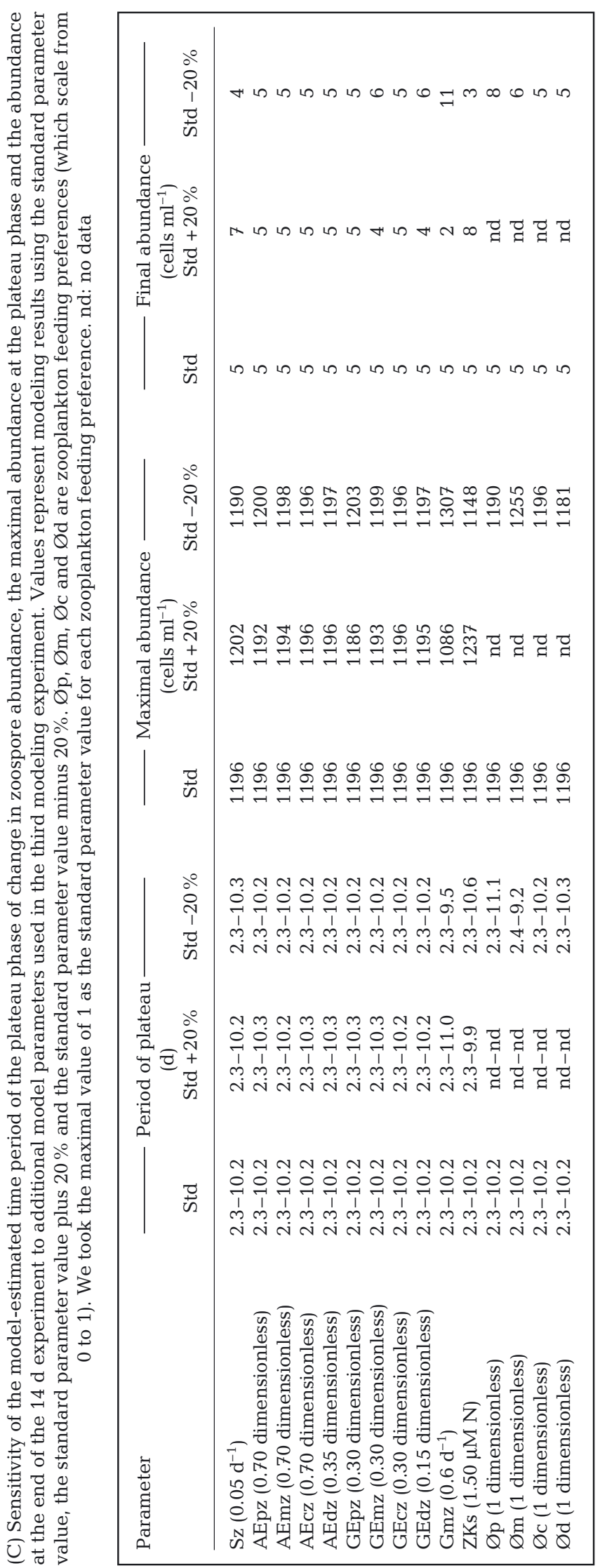

mental observations $r^{2}=0.90[p<0.05]$, the slope is not significantly different from 1 [ $p<0.05]$, the intercept is not significantly different from 0 [p $<0.05]$ [Figs. 2B $\& 3 \mathrm{~B}]$ ), i.e. initial quick increase in abundance, followed by a plateau, and ultimate decline of the zoospore abundance. In addition, the model reproduces, the time period of the plateau phase (from Day 2.4 to 7.7 in the model simulation and from Day 2 to 8 in the laboratory experiment), the maximal abundance at the plateau phase (1773 and 1706 cells ml $^{-1}$ in the simulation laboratory experiment, respectively), and the abundance at the end of the $14 \mathrm{~d}$ experiment (56 and 58 cells ml ${ }^{-1}$ in the simulation and laboratory experiment, respectively) (Figs. 2B \& 3B).

In both the model and the observations, the Pfiesteria size increases very quickly on Day 1 (Figs. 2B \& 3B). In the model, the size of Pfiesteria zoospores continues to increase in Day 2 because the amount of nitrogen assimilated is still larger than the metabolic nitrogen losses. When the size of Pfiesteria zoospores reaches the maximum size, they undergo cell division. The consequence of the cell division is that the size of the zoospores decreases to half of the maximum size and the abundance of the zoospores doubles. In the model run, the Pfiesteria zoospores divide on Days 1 and 2 (Fig. 3B). After phytoplankton food is exhausted (in Day 4), the size of zoospores begins to decrease at a constant rate due to starvation and their size reaches the critical size on Day 8 (Fig. 3B).

The time-dependent change of the size of zoospores in the model experiment is generally consistent with the laboratory observations (correlation coefficient $\mathrm{r}=$ $0.76, p<0.05$ (Figs. 2B \& 3B). However, the model predicts that the zoospore mean diameter should be smaller on Day 12 compared to Day 6, whereas the observations indicate the opposite (Figs. 2B \& 3B). This discrepancy between the model results and laboratory experiment is either due to experimental/measurement error or some physiological processes that we do not include in our model.

The Pfiesteria biomass builds up very quickly in the first $2 \mathrm{~d}$ of the model run when food is available, reaches a maximum on Day 2, and then declines due to starvation after the phytoplankton prey is depleted (Fig. 3A). Therefore, in the model, zoospore biomass is regulated effectively by bottom-up control (food availability). It can be seen from the first $2 \mathrm{~d}$ of the simulation that the biomass of Pfiesteria zoospores increases faster during the light periods than during the dark periods (Fig. 3A). Laboratory observations have confirmed that the light does, indeed, enhance the growth of zoospores (Anderson et al. 2003b). In the model, this effect is due to the photosynthetic activity of kleptochloroplasts of zoospores, which is consistent with experimental studies on Pfiesteria nutrient uptake 
kinetics which suggest that light enhances the nutrient uptake of zoospores (Lewitus et al. 1999, Stoecker 1999).

For the sake of simplicity, we did not include the retention effect of kleptochloroplasts in this model. If we had, we would have had to consider the photosynthetic activity of both the currently acquired kleptochloroplasts and the previously acquired kleptochloroplasts that still keep their functionality. In reality, the photosynthetic activity of kleptochloroplasts is probably more significant during the period when phytoplankton food is replete and likely persists for some period of time even after phytoplankton are depleted. Thus, with a retention time, the rate of increase in zoospore biomass would be faster than that in the current model during the period of replete phytoplankton food conditions (combined effect of the newly and previously acquired kleptochloroplasts). Hence, the rate of decrease in zoospore biomass would be slower than in the current model during the initial period of phytoplankton depletion. Moreover, the rate of decrease in zoospore biomass would be same as that in the current model after all the previously acquired kleptochloroplasts lost their functionality.

\section{Second modeling experiment}

In the second modeling experiment, we implemented the trigger for the transformation of Pfiesteria zoospores to Pfiesteria cysts. We have discussed the rationale of the trigger design in 'Model'. The major objective of this modeling experiment is to demonstrate effects of the transformation of Pfiesteria zoospores to Pfiesteria cysts on Pfiesteria population dynamics. The results of this experiment are similar to the results of the first model experiment, except for the transformation of zoospores to cysts that is triggered from Day 4.5 to 6.2 due to the prolonged phytoplankton depletion (Fig. 4). Both cyst abundance and biomass reach the maximum at the end of the transformation period (Day 6.2) (Fig. 4). Although phytoplankton biomass was exhausted by zoospore grazing on Day 3 (Fig. 4A), the transformation from zoospores to cysts was not triggered until Day 4 when the size of the zoospores falls within a predefined size window for encystment (Fig. 4B).

The transformation mechanism of Pfiesteria zoospores to Pfiesteria cysts in the second modeling experiment is consistent with laboratory and field observations, which suggest that encystment is triggered during adverse conditions such as starvation (Corliss \& Esser 1974, Anderson 1997, Anderson et al. 2003a, J. M. Burkholder pers. comm.). However, Pfiesteria zoospores can form 2 kinds cysts (Burkholder \& Glasgow 1997, Anderson et al. 2003a). Our most recent laboratory experiments with NON-IND Pfiesteria zoospores show that the environmental conditions for the formation of these 2 types of cysts are different: one type of cyst (cyst 'A', Anderson et al. 2003a) forms after zoospores deplete their prey regardless of light intensity; whereas another type of cyst (cyst 'B', Anderson et al. 2003a) forms after zoospores deplete their prey only when exposed to at least $24 \mathrm{~h}$ of complete darkness (Anderson et al. 2003a).

In addition to starvation, other kinds of environmental stress, such as sudden shift in temperature or salinity, or physical disturbance, can trigger encystment (Burkholder \& Glasgow 1997). Thus, it appears that the trigger mechanism in the model, which is based upon size associated with food availability, is not sufficient to represent the transformation mechanism for all of the different types of Pfiesteria cysts in nature. Clearly, different kinds of trigger mechanisms need to be developed to deal with the transformations of the different types of cysts. Because information on the factors which control the encystment of Pfiesteria is incom-
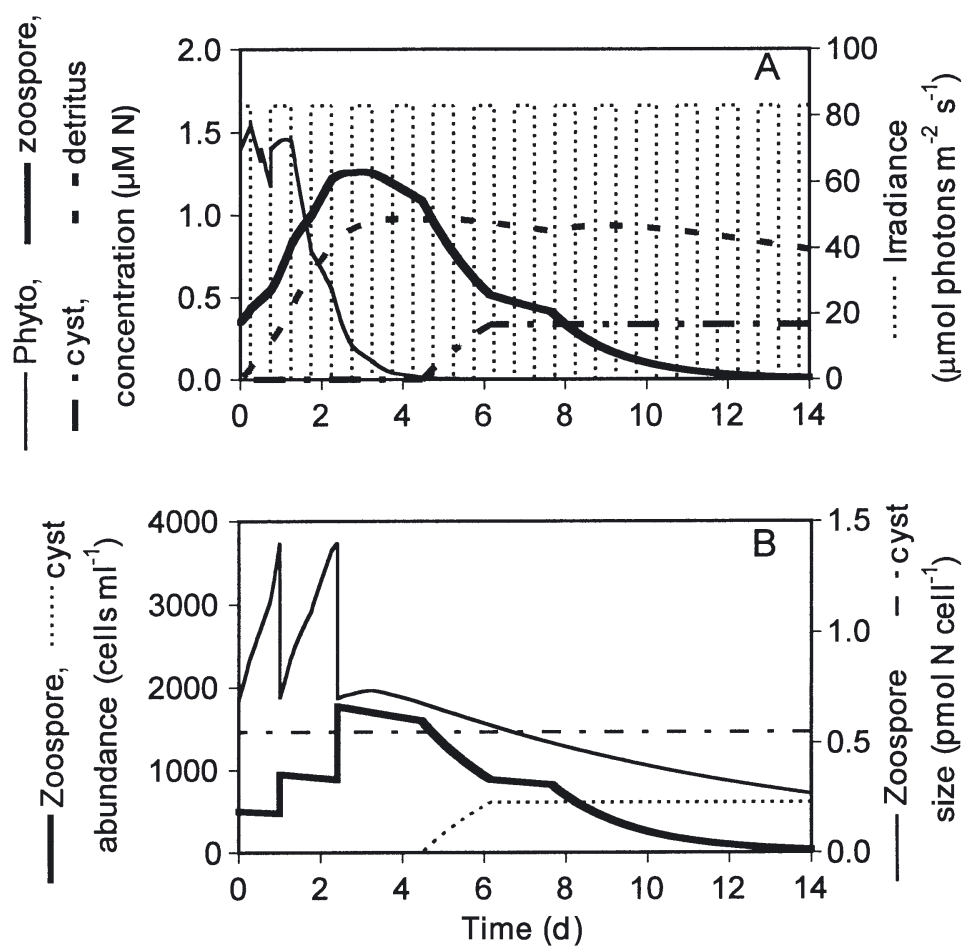

Fig. 4. Second modeling experiment. All terms and conditions are the same as the first modeling experiment except for the addition of stage transform between zoospores and cysts. (A) Pfiesteria zoospore biomass, Pfiesteria cyst biomass, phytoplankton biomass and detritus concentration versus time. Nutrient concentration is off-scale and is not shown.

(B) Pfiesteria zoospore/cyst abundance and size versus time 
plete (Burkholder \& Glasgow 1997), it would be unrealistic to build a completed trigger mechanism in this current model. The trigger mechanism in the model, which is based primarily on general principles and observations from a wide range of dinoflagellate species, should be considered as a starting point for development of more completed trigger mechanisms for Pfiesteria and other dinoflagellates.

\section{Third modeling experiment}

Zooplankton have been observed to consume Pfiesteria zoospores (Burkholder \& Glasgow 1995, Mallin et al. 1995, Stoecker et al. 2000, M.R. Roman unpubl.). In the third modeling experiment, we added zooplankton grazing to evaluate the role of zooplankton grazing on the regulation of Pfiesteria populations. Like the first modeling experiment, Pfiesteria zoospores also divide on Days 1 and 2 (Fig. 5B). After doubling, the abundance of zoospores decreases faster in the third modeling experiment than in the first due to the extra loss term from zooplankton grazing (Fig. 5B). The timedependent change of the size of zoospores is almost identical between the first modeling experiment and
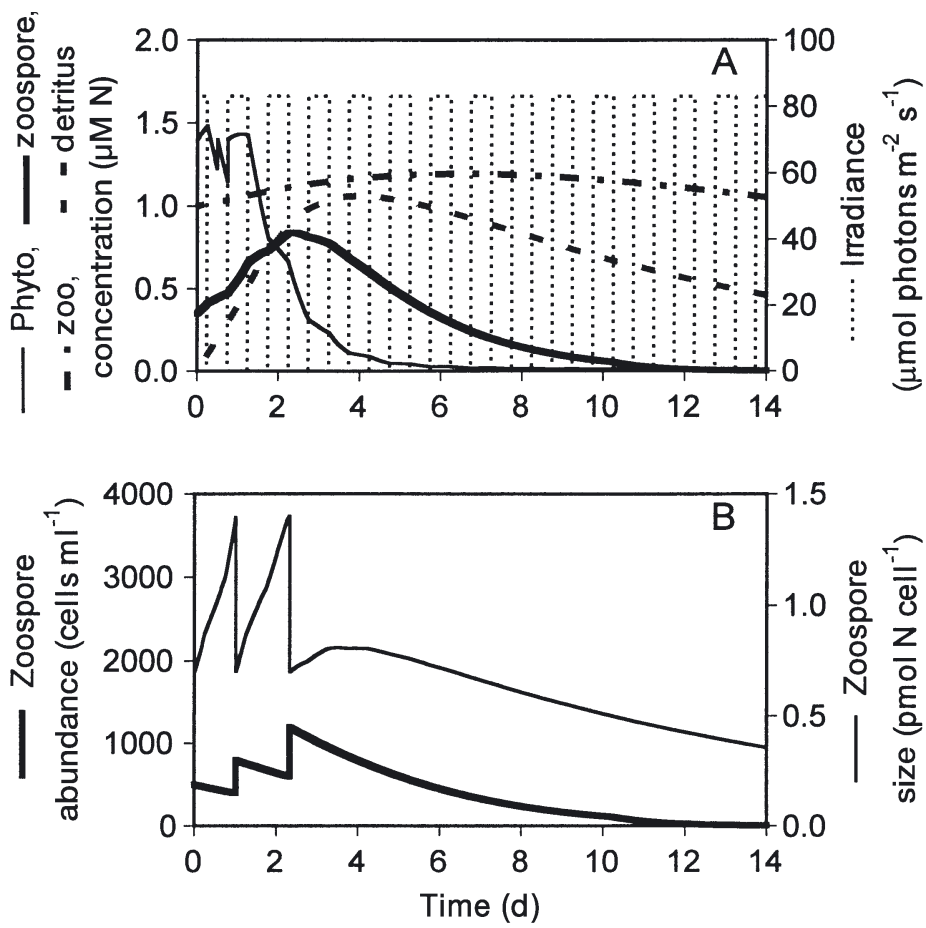

Fig. 5. Third modeling experiment. All terms and conditions are the same as the first modeling experiment except for the addition of mesozooplankton component. (A) Pfiesteria zoospore biomass, phytoplankton biomass, zooplankton biomass and detritus concentration versus time. Nutrient concentration is off scale and is not shown. (B) Pfiesteria zoospore abundance and size versus time the third (Figs. 3B \& 5B). The maximum zoospore biomass in the third modeling experiment is lower than in the first, and the zoospore biomass decline is much faster in the third modeling experiment than in the first due to the extra loss term from zooplankton grazing (Figs. 3A \& 5A). The results of the third modeling experiment show that the Pfiesteria zoospore population in our simulations can be regulated effectively by the top-down grazing control, which is consistent with laboratory observations (Stoecker \& Gustafson 2002, Stoecker et al. 2002, M.R. Roman unpubl.).

\section{Model sensitivity}

We developed this model to capture the major characteristics of the time-dependent change in Pfiesteria zoospore abundance that were observed in a laboratory experiment, and also to provide a general trigger mechanism for encystment and to reveal potential impacts of grazing. However, the values we assigned to the parameters show large variations in the literature, and many are based upon organisms other than Pfiesteria. To evaluate the effects of changing the values of the model parameters on the results, we increased and decreased the values of model parameters and reran the model simulations. The effects of these parameter adjustments are reported in Table 3. We summarize the major conclusions of the sensitivity analysis as follows.

In the first modeling experiment, we attempted to mimic our laboratory results. For the sake of brevity, we report only the effects of parameter adjustments on the model-estimated time period of the plateau phase in zoospore abundance, the maximal abundance at the plateau phase and the abundance at the end of the $14 \mathrm{~d}$ experiment (Fig. 3, Table 3A). Here ,we define that the plateau phase in zoospore abundance starts at the point when the abundance reaches the maximum and ends at the point when the size of zoospores decreases to the critical value (0.5 pmol N, Table 2) (Fig. 3) that induces increased mortality due to starvation (from 0.05 to $0.5 \mathrm{~d}^{-1}$ ). Beyond this point, the abundance of zoospores quickly declines (Fig. 3). To quantify how changes in the parameter values impact the overall fit of the model to the data, we ran linear regression analyses on the model predicted versus the experimental zoospore abundance. If the regression coefficient is significant ( $p<0.05)$, then the slope is not significantly different from $1(\mathrm{p}<0.05)$ and the intercept is not significantly different from 
$0(p<0.05)$. Hence, we conclude that the difference in the time-dependent changes in zoospore abundance between the model and the experimental observations are in reasonably good agreement.

The results of the first modeling experiment are not very sensitive to the changes in most of the parameter values. However, the model can be significantly affected by changes in the values of Mmax, AEm, AEXm, $\mu_{\mathrm{mp}}$ and Ik (Table $3 \mathrm{~A}$ ). The results are sensitive to these parameters because they are key parameters that directly affect the division time (Mmax), growth rate (AEm, AEXm and Ik) and the food supply of zoospores ( $\mu_{\mathrm{mp}}$ and Ik).

The major objective of the second modeling experiment was to demonstrate the trigger mechanism for encystment and the effects of the transformation of Pfiesteria zoospores to cysts on Pfiesteria population dynamics. Here, we evaluated only those additional parameters that were used in the second modeling experiment. For the sake of brevity, we used changes in the model-estimated time period of the transformations from zoospores to cysts and the maximal cyst abundance at the end of the transformation period (Fig. 4) to evaluate the effects of varying the model parameters. Here, we find that the model-estimated time period of the transformations from zoospores to cysts is not very sensitive to the changes in the parameter values. However, the maximal cyst abundance at the end of the transformation can be significantly affected by the changes in the values of these parameters (Table 3B) because these parameters directly affect either the period of the transformation or the rate of the transformation.

The major objective of the third modeling experiment was to evaluate the role of zooplankton grazing on the regulation of Pfiesteria populations. Here, we evaluated only those additional parameters that were used in the third modeling experiment. Like the sensitivity test of the first modeling experiment, we used changes in the model-estimated time period of the plateau phase of change in zoospore abundance, the maximal abundance at the plateau phase, and the abundance at the end of the $14 \mathrm{~d}$ experiment (Fig. 5) to evaluate the effects of varying the model parameters. Once again, the model results are generally not very sensitive to the changes in the parameter values. However, the model-estimated maximal abundance at the plateau phase can be significantly affected by the changes in the value of Gmz (Table 3C) because this parameter directly affects the grazing pressure of zooplankton on zoospores.

Although the model results are dependent on the values of the model parameters, the general conclusions and the patterns of the time-dependent variations of Pfiesteria populations (e.g. abundance, size, biomass and encystment etc.) are not very sensitive to the changes in the parameter values. Thus, the conclusions that we have drawn based upon our initial choice of parameter values should not be greatly affected if the values change. Nonetheless, many more experimental data are needed to validate the values of model parameters, particularly those that the model is more sensitive to, such as Mmax, AEm, AEXm, $\mu_{m p}$ Ik, Mu, $\mathrm{Ml}$ and Tmc.

\section{Model validation note}

In the foregoing analyses, we have used data derived from a single laboratory experiment to validate our model. It should be noted, however, that the model was also tuned to fit these data, i.e. some parameter values were adjusted to maximize the agreement between the model and the data. Strictly speaking, one cannot test a model with the data that were used to formulate it. However, to develop this model, we have drawn on a much larger pool of information, which includes several previous modeling studies and laboratory studies on Pfiesteria and related species, i.e. the vast majority of the data and information that went into the model development process were derived from other sources. Therefore, we believe that the comparisons with the experimental data represent a legitimate validation of the model. We also reiterate that the major focus of the paper is to present a new model of Pfiesteria population dynamics. Thus, the emphasis here is on model development, and to a lesser extent on validation. Clearly, much more work needs to be done to fully validate this model.

\section{CONCLUSIONS}

Here, we present a generalized, dynamic numerical model designed to simulate Pfiesteria population dynamics based upon available observations and literature. This effort mainly focuses on NON-IND forms of Pfiesteria because NON-IND Pfiesteria represent some $40 \%$ of natural populations, and they have a less complex life cycle which makes them easier to model. With this model, we are able to follow the time dependency of both individual cell size and abundance of zoospores, which provides a means to represent some of the unique aspects of Pfiesteria population dynamics, such as transformations from zoospores to cysts and zoospore mortality rate, which are believed to be closely related to cell size.

This model successfully reproduces not only the pattern of the 3 phases of change in zoospore abundance that are observed in a batch laboratory experiment 
(initial quick increase in abundance, followed by a plateau and ultimate decline of the zoospore abundance), but also the time period of the plateau phase, the maximal abundance at the plateau phase and the abundance at the end of the $14 \mathrm{~d}$ experiment.

We also illustrate some hypothetical mechanisms in Pfiesteria population dynamics through 2 additional modeling experiments: these experiments are, in fact, model predictions. We have developed a possible trigger mechanism for the transformation of Pfiesteria zoospores to Pfiesteria cysts. This trigger is based on the idea that at some point starvation will induce cyst formation and that there is a size-based window of opportunity for cyst formation. Although this mechanism is confirmed by some observations, recent laboratory experiments indicate that the trigger mechanism we used in the model may not always be sufficient to represent the transformation mechanism for the different types of Pfiesteria cysts in nature. This suggests that different kinds of trigger mechanisms will need to be developed to deal with the transformations of the different types of cysts. The results of our third modeling experiment suggest that NON-IND Pfiesteria zoospores can be regulated effectively by top-down control due to zooplankton grazing. There is already some experimental evidence which suggests that this model prediction is correct, and that microzooplankton may be particularly effective grazers of NON-IND Pfiesteria (Stoecker \& Gustafson 2002, Stoecker et al. 2002, M.R. Roman unpubl.). However, the relevance of this model prediction to the population dynamics of toxic forms of Pfiesteria is still uncertain, i.e. toxicity may confer some immunity to zooplankton grazing losses.

The model results are generally not very sensitive to the changes in most of the parameter values. However, the model-estimated time period of the plateau phase in zoospore abundance, the maximal abundance at the plateau phase and the abundance at the end of the $14 \mathrm{~d}$ experiment can be significantly affected by the changes in the values of Mmax, AEm, AEXm, $\mu_{\mathrm{mp}}$, Ik and Gmz. These are the key parameters that affect the division time, growth rate, the food supply of zoospores and the grazing pressure of zooplankton on zoospores. However, these parameter values are not well constrained at present time. In terms of cyst transformation, the maximal cyst abundance at the end of the transformation period can be significantly affected by the changes in the values of $\mathrm{Mu}, \mathrm{Ml}$ and Tmc. Unfortunately, these parameter values are poorly known. Additional experimental measurements are needed to constraint the values of these parameters. Having the appropriate values of the key parameters should improve the accuracy of the model simulations and predictions; however, we do not anticipate that they will fundamentally alter our conclusions.
The model presented here should have a range of applications because it can be used to simulate data sets in which changes in population size are reported in terms of abundance and/or total population mass. Changes in cell size, in relation to food availability and other environmental conditions, can in turn be used as the basis for modeling a wide variety of cell-sizedependent physiological functions in organisms, including growth, metabolism and reproduction.

Acknowledgements. The authors are grateful to Drs. M. R. Roman, D. K. Stoecker and J. M. Burkholder for their input and advice, and to Dr. P. M. Glibert for her leadership in the multi-institutional ECOHAB project under which this work was carried out. This research was directly supported by NOAA-ECOHAB grant NA86OP0493 awarded to R.R.H., and indirectly by continuing NSF support to R.R.H. This manuscript is contribution number 3669 for the UMCES.

\section{LITERATURE CITED}

Andersen V, Nival P (1986) A model of the population dynamics of salps in coastal waters of the Ligurian Sea. J Plankton Res 8:1091-1110

Anderson DM (1997) Bloom dynamics of toxic Alexandrium species in the northeastern US. Limnol Oceanogr 42: $1009-1022$

Anderson JT, Stoecker DK, Hood RR (2003a) Formation of two types of cysts by a mixotrophic dinoflagellate, Pfiesteria piscicida. Mar Ecol Prog Ser 246:95-104

Anderson JT, Hood RR, Zhang X (2003b) Quantification of Pfiesteria piscicida growth and encystment parameters using a numerical model. Mar Ecol Prog Ser 246: 105-113

Arkinson A (1995) Omnivory and feeding seclectivity in five copepod species during spring in the Bellingshausen Sea, Antarctica. ICES J Mar Sci 52:385-396

Burkholder JM, Glasgow HB Jr (1995) Interactions of a toxic estuarine dinoflagellate with microbial predators and prey. Arch Protistenkd 145:177-188

Burkholder JM, Glasgow HB Jr (1997) Pfiesteria piscicida and other Pfiesteria-like dinoflagellates: Behavior, impacts, and environmental controls. Limnol Oceanogr 42: 1052-1075

Burkholder JM, Noga EJ, Hobbs CH, Glasgow HB Jr, Smith SA (1992) New 'phantom' dinoflagellate is the causative agent of major estuarine fish kills. Nature 358:407-410

Burkholder JM, Glasgow HB Jr, Hobbs CH (1995) Fish kills linked to a toxic ambush-predator dinoflagellate: distribution and environmental conditions. Mar Ecol Prog Ser 124: 43-61

Burkholder JM, Glasgow HB Jr, Deamer-Melia NJ (2001) Overview and present status of the toxic Pfiesteria complex. Phycologia 40:186-214

Caron DA, Goldman JC, Fenchel T (1990) Protozoan respiration and metabolism. In: Capriulo GM (ed) Ecology of marine protozoa. Oxford University Press, Oxford, p 307-322

Carlotti F, Sciandra A (1989) Population dynamics model of Euterpina acutifrons (Copepoda; Harpacticoida) coupling individual growth and larval development. Mar Ecol Prog Ser 56:225-242

Carlotti F, Giske J, Werner F (2000) Modeling zooplankton dynamics. In: Harries RP, Wiebe PH, Lenz J, Skjoldal HR, 
Huntley M (eds) Zooplankton methodology manual. Academic Press, London, p 571-667

Corliss JO, Esser SC (1974) Comments on the role of cyst in the life cycle and survival of free-living protozoa. Trans Am Microsc Soc 93:578-593

Donaghay PL, Osboun TR (1997) Toward a theory of biologicalphysical control of harmful algal bloom dynamics and impacts. Limnol Oceanogr 42:1283-1296

Fasham MJR, Ducklow HW, McKelvie SM (1990) A nitrogenbased model of plankton dynamics in the oceanic mixed layer. J Mar Res 48:591-639

Fenchel T (1982) Ecology of heterotrophic microflagellates, III. Adaptations to heterogeneous environments. Mar Ecol Prog Ser 9:25-33

Fenchel T, Finlay BJ (1983) Respiration rates in heterotrophic, free-living protozoa. Microb Ecol 9:99-122

Franks PJS (1997) Models of harmful algal blooms. Limnol Oceanogr 42:1273-1282

Gifford DJ, Dagg MJ (1988) Feeding of the estuarine copepod Acartia tonsa Dana: carnivory vs hervory in natural microzooplankton assemblages. Bull Mar Sci 43:458-468

Glasgow HB Jr, Lewitus AJ, Burkholder JM (1998) Feeding behavior of the ichthyotoxic estuarine dinoflagellate, Pfiesteria piscida, on amino acids, algal prey, and fish vs mammalian erythrocytes. In: Reguera B, Blanco J, Fernández ML, Wyatt T (eds) Harmful algae. Xunta de Galicia and Intergovernmental Oceanographic Commission, UNESCO, Paris, p 394-397

Hood RR, Bates NR, Capone DG, Olson DB (2001) Modeling the effect of nitrogen on carbon and nitrogen fluxes at BATS. Deep-Sea Res II 48:1609-1648

Kishi M, Ikeda S (1986) Population dynamics of 'red tide' organisms in eutrophicated coastal water-numerical experiment of phytoplankton bloom in the east Seto Inland Sea, Japan. Ecol Model 31:145-174

Editorial responsibility: Otto Kinne (Editor),

Oldendorf/Luhe, Germany
Lewitus AJ, Glasgow HB Jr, Burkholder JM (1999) Kleptoplastidy in the toxic dinoflagellate Pfiesteria piscicida (Dinophyceae). J Phycol 35:303-312

Li A (1998) The feeding, physiology, and ecology of the mixtrophic dinoflagellate Gyrodinium galatheanum. PhD dissertation, University of Maryland, College Park, MD

Mallin MA, Burkholder JM, Larsen LM, Glasgow HB Jr (1995) Response of two zooplankton grazers to an ichthyotoxic estuarine dinoflagellate. J Plankton Res 17:351-363

McCreary JP Jr, Kohler KE, Hood RR, Olson DB (1996) A four-component ecosystem model of biological activity in the Arabian Sea. Prog Oceanogr 37:193-240

Steele J (1974) The structure of marine ecosystem. Harvard University Press, Cambridge, MA

Stickney HL, Hood RR, Stoecker DK (2000) The impact of mixotrophy on planktonic marine ecosystems. Ecol Model 125:203-230

Stoecker DK (1998) Conceptual models of mixotrophy in planktonic protists and some ecological and evolutionary implications. Eur J Protistol 34:281-290

Stoecker DK (1999) Mixotrophy among dinoflagellates. J Eukaryot Microbiol 46(4):397-401

Stoecker DK, Gustafson DW Jr (2002) Prediction grazing mortality of an estuarine dinoflagellate, Pfiesteria piscicida. Mar Ecol Prog Ser 233:31-38

Stoecker DK, Stevens K, Gustafson DW Jr (2000) Grazing on Pfiesteria piscicida by microzooplankton. Aquat Microb Ecol 22:261-270

Stoecker DK, Parrow MW, Burkholder JM, Glasgow HB Jr (2002) Grazing by microzooplankton on Pfiesteria piscicida cultures with different histories of toxicity. Mar Ecol Prog Ser 28:79-85

Wyatt T, Horwood J (1973) Model which generates red tides. Nature 244:238-240

Submitted: November 27, 2001; Accepted: January 23, 2003

Proofs received from author(s): June 20, 2003 